\title{
Kronik ağrılı hastada psikiyatrik tedaviler
}

\author{
Psychiatric treatments in patients with chronic pain
}

\author{
Özen Önen Sertöz
}

Ege Üniversitesi Tıp Fakültesi Ruh Sağlığı ve Hastalıkları Anabilim Dalı, Konsültasyon Liyezon Psikiyatrisi Bilim Dalı, İzmir

Bu yazıda, kronik ağrılı hastaların psikiyatrik tedavi yöntemleri biyo-psikososyal modele göre özetlenmiş; kronik ağrıda uygulanan psikiyatrik ilaçlar ve psikososyal müdahaleler, literatüre dayanarak gözden geçirilmiştir.

Anahtar sözcükler: antidepresanlar; kronik ağrı; psikososyal müdahaleler
In this paper, psychiatric treatment methods for chronic pain patients are summarized according to the bio-psychosocial model, and psychiatric drugs and psychosocial interventions used in chronic pain patients are reviewed on the base of related literature.

Key words: antidepressants; chronic pain; psychosocial interventions

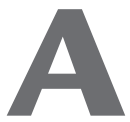

ğrının üç boyutu, Melzack ve Casey tarafından tanımlanmıştır: duyusal boyut (sensory-discriminative), duygusal-emosyonel boyut (affective-motivational) ve bilişsel boyut (cognitive-evaluative). ${ }^{[1]}$ Günümüzde kronik ağrının fizyolojik, emosyonel, bilişsel, sosyal ve çevresel faktörlerin birbirleriyle olan karmaşık ilişkileri sonucunda geliştiği kabul edilir. ${ }^{[2]}$ Kronik ağrılı durumlar, dünyada diğer sağılk sorunları içerisinde uzun yıllar en fazla yeti-yitimiyle yaşamaya neden olan hastalıklardır. Bireylerin hayatında büyük ölçüde sıkıntı ve strese neden olan bu durumların tedavisinde, biyo-psikososyal model temel alınarak yapılan multidisipliner yaklaşımlar, tedavi başarısını arttırır. ${ }^{[3,4]}$ Ağrılı hastaların pek çoğu, bu durumun onların iş, sosyal, romantik ve eğlence-dinlence faaliyetlerini olumsuz etkilediğini belirtir. Hastalarımızın dile getirdiği bu bilgiler, hastalıkların bir nevi biyo-psikososyal modelini açıklar.

Biyo-psikososyal model ağrıyı -bütünüyle fizyolojik süreçlerin bir sonucu olarak ortaya çıktığını öne süren biyomedikal görüş ya da altta yatan psikolojik güçlüklerin ve zorlamaların kendini ifade etme şekli olduğunu öne süren psikojenik görüşten farklı olarak- biyolojik, sosyolojik ve sosyokültürel değişkenlerin karşılıklı etkileşimi ile ortaya çıkan bir süreç olarak görür. ${ }^{[1]} \mathrm{Bu}$ değişkenlerin karmaşık etkileşimi ile, ağrı algısında pek çok bireysel farklılıklar ortaya çıkar. Ağrı yaşantısı süreç içinde, ağrı sinyallerinin iletiminde rol oynayan fiziksel faktörler, bu sinyallerin yorumlanmasında rol oynayan psikolojik ve emosyonel faktörler ve ağrının düzelmesini teşvik eden ya da caydırıcı olabilecek (pekiştireçler; ikincil kazanç) çevresel faktörlerin varlığından etkilenir. ${ }^{[1]}$

Kronik ağrı hastasını biyo-psikososyal model çerçevesinde değerlendirmek, her zaman hastada psikiyatrik bir hastalığın bulunması gerekliliğini içermez. Kronik ağrı tedavisinde, hem tıbbi hem de psikiyatrik uygulamalar bir arada olmalıdır. Bazı hastalar sadece tıbbi tedavilere yanıt verirken, bazıları tıbbi ve psikiyatrik tedavilerden birinin eklenmesine daha iyi yanıt verebilir.

Kronik ağrılı hastada psikiyatrik tedaviler, genellikle şu durumlarda uygulama alanı bulur:

1- Psikiyatrik hastalığın kendisi, ağrı yakınmasının nedenidir.

2- Ağrının organik etiyolojisi belirlenmiştir, fakat uygulanan etkin doz ve sürede tıbbi tedavilere rağmen hastanın yakınmaları beklenenin üzerindedir veya hiç geçmemiştir. Bu durumlarda, kronik ağrıya sıklıkla eşlik edebilecek komorbid psikiyatrik hastalıklar (depresyon, anksiyete bozuklukları, madde kullanım bozuklukları opioid bağımlılı̆̆ı) değerlendirilmelidir.

3- Ağrı nöropatiktir.

- Illetişim adresi: Prof. Dr. Özen Önen Sertöz, Ege Üniversitesi Tıp Fakültesi Ruh Sağlığı ve Hastalıkları Anabilim Dalı, Bornova, İzmir Tel: 0532 - 7498747 e-posta: onensertoz@gmail.com

- Geliş tarihi: 20 Șubat 2017 Kabul tarihi: 20 Șubat 2017 


\section{KRONIK AĞRILI HASTAYA PSIKIYYTRIK YAKLAŞIM}

Kronik ağrısı olan hastaya psikiyatrik yaklaşım çerçevesinde en önemli adım, hastayı sahiplenmektir. Hastayı empati ile ve samimiyetle dinlemek, yakınmalarını önemsemek ve hastanın mahremiyetine saygı göstermek, iyi bir hasta-hekim ilişkisinin gelişmesi ve tedavilere uyum açısından kritik öneme sahiptir. Kronik ağrıya yönelik tıbbi tedaviler uygulanmakta iken, hastanın psikolojik ve sosyal ihtiyaçlarının neler olduğuna duyarlı olmak, bu açılardan hastayı değerlendirmek, her zaman aktif psikiyatrik tedavilere başlama noktasına ulaşmayabilir. Bazen, hastanın psikolojik ihtiyaçlarını empatiyle dinleyebilmek, gerekli sosyal ve çevresel düzenleme önerilerinde bulunmak yeterli olabilir. ${ }^{[5]}$

Kronik ağrılı bir hasta psikiyatrik değerlendirme için yönlendirilmiş ise, aklımıza sıklıkla tıbbi tedavilerin işe yaramadığı, hastanın tedavilere uyumsuz olduğu veya ağrının ne kadar organik ne kadar psikojenik kökenli olduğunun tam olarak ayrımının yapılamadığı gelir. Psikiyatriye yönlendirilen hastalar, genellikle "zor, uyumsuz, problemli" olarak tanımlanırlar. Bu hastalar içerisinde, psikojenik kökenli ağrısı olanlar, psikolojik ve organik faktörlerin bir arada rol oynadığı ağrılı durumları olan hastalar veya organik nedenli ağrısı olan hastalar yer alır. Son grubu oluşturan hastaların, psikiyatrik açıdan görece sağlıklı bireyler olduğunu düşünebiliriz. Fakat, yaşamlarının bir kısmını kronik ağrıyla geçirmek zorunda kalmışlardır ve bu süreç içerisinde bir takım psikiyatrik yakınmalar veya rahatsızlıklar geliştirmiş olabilirler. Bu hastaları ilk iki grup hastadan ayırmada en çok işimize yarayacak bilgiyi, bu hastaların kronik ağrı öncesi yaşam tarzları, kişilik özellikleri, premorbid uyumları ve sosyal-mesleki-kişilerarası işlevselliklerini sorgulayarak elde edebiliriz. ${ }^{[5]}$

Kronik ağrılı hastayı değerlendirirken, özellikle aşağıda belirtilen durumlara dikkat edilerek ayrıntılı bilgi edinilmelidir.

1- Ağrının etiyolojisi doğru tanılandırılmış $m ı$ ?

2- Hasta kültüründe ağrının işlevi ve anlamı ne?

3- Hasta intihar riski taşımakta mı?

4- Madde kullanım bozuklukları eşlik ediyor mu?

5- Erken çocukluk çağı travmaları öyküsü var mı?

6- Aile içi şiddet öyküsü var mı?

7- Travma sonrası stres bozukluğu eşlik ediyor mu?

8- Daha önce yasal sorun yaşayıp yaşamadığı.

9- Kullandığı ilaçların listesi.

10- İdrar toksikoloji analizi.
Atipik seyreden bazı tıbbi hastalıklarda da -multipl skleroz gibi- ağrının etiyolojisi tam olarak aydınlatılamamış olabilir. Bu nedenle, ağrılı hastaya psikiyatrik tedaviler uygularken, organik etiyoloji ihtimalini aklımızın bir köşesinde hep canlı tutmakta yarar vardır.

Kültürel olarak yapılması ve söylenmesi kabul görmeyen durumlar olabilir. Eğer hastanın yaşadığı kültürde ruhsal sıkıntıları dile getirmek pek kabul görmüyor ise, ruhsal sıkıntı yerine bedensel yakınmayı dile getirmek, daha çok ilgi görme veya dikkate alınmaya olanak sağlayabilir. Pek çok kültürde, depresyon ve anksiyete bireyin zayıflığı olarak da görülür veya "deli" olarak algılanmalarına neden olabilir. Ruhsal sıkıntı veya çatışmanın bedensel bir belirti olarak ifade bulması, kişinin "rahatlamasına" neden olurken, ruhsal sıkıntı aynı zamanda toplumca daha kabul edilebilir bir hale bürünmüş olur. Bu durumlarda izlenecek yol haritası; altta yatan psikiyatrik hastalığı tedavi etmek ve aileye ve hastaya psiko-eğitim vermektir. ${ }^{[6]}$

Kronik ağrı, tek başına intihar nedeni olmasa da, intihar açısından riskli olabilecek majör depresyon, madde kullanım bozuklukları ve umutsuzluğu alevlendirebilir. ${ }^{[7]}$

Kronik ağrılı hastayı değerlendirirken; kullandığı ilaçların kimler tarafından reçete edildiği, bu ilaçları hangi amaçla aldığı ve nasıl kullandığı ayrıntılandırılmalıdır. Tedaviye uyumsuzluk, amacı dışında ilaç kullanmak, fazladan ilaç almak gibi durumların tespit edilmesi, bize hastanın tedavi motivasyonu hakkında bilgi verebilir. Bu bilgiler, hastanın bilgisi dahilinde olmak üzere, tedavisini yöneten diğer hekimlerce de paylaşılmalıdır.

\section{KRONIK AĞRILI HASTADA PSIKIYATRIK TEDAVININ ILKELERI}

\section{Basamaklı Tedavi Yaklaşımı}

Bu tedavi yaklaşımında, hastanın bir önceki tedaviye yanıtı ve mevcut durumun tedavisinde öz-bakımına dahil olmaya ne kadar hazır olup olmadığı değerlendirilerek, tedavi basamağı belirlenir. ${ }^{[8]}$ Bu tedavi yaklaşı$\mathrm{mı}$, alkol ve sigara kullanımı veya kolesterol düzeylerini düşürme gibi pek çok tıbbi durumun ve sağlık davranışının tedavisinde başarıyla uygulanmıştır. ${ }^{[9]}$

\section{Birinci basamak}

Kronik ağrı amacıyla tedavi arayışı içinde olan tüm hastalara uygundur. Bu aşamada hasta, ağrı kesici tedaviler almaktadır. Psikiyatri hekiminin rolü, hastayı yönlendiren hekime hastanın ağı ile ilişkili kaygılarını araştırması ve hastanın öz-bakımına dahil olması için motivasyonunun nasıl arttırılabileceği konusunda rehberlik etmektir. Örneğin; pek çok hasta ağrı nedeniyle cinsellik, 
egzersiz gibi fiziksel aktivitelerden kaçar. Bu korku doğru bilgilendirmeyle en aza indirilebilir. Hastaya, ağrıya rağmen aktif kalmanın yararları anlatılır ve ona zararı dokunmayacak düzeyde aktif yaşantısına dönmesi için destek olunur. Birinci basamak tedavide, motivasyonel görüşme teknikleriyle yapılan hasta görüşmeleri olumlu sonuçlar verir. Bu görüşmelerde, hastanın ağrısına yönelik tedavilere iliş̧in gerçekçi olmayan beklentileri ortaya çıkarılabilir. Hasta, öz-bakım stratejilerini kullanması için desteklenir, hatta biraz zorlanabilir; ağrısının alevlenme dönemlerinde onunla nasıl başa çıkacağına ilişkin planlar oluşturmasına yardımcı olunur. ${ }^{[6]}$

Kronik ağrısı olan hastaya öz-yönetim öğretilmelidir. Öz-yönetimi sağlayabilmesi için, ağrılarının altında yatan fizyolojik mekanizmalar ve verilen tedavilerin etkinlikleri hakkında hastaya eğitim, önerilen ilaç tedavisine uyum açısından sorumluluk verilir. Hastalar bu şekilde öz-bakımlarına dahil edilebilirler.

\section{ikinci basamak}

Ağrı tedavisinde daha aktif bir yaklaşıma ihtiyaç duyan hastalar için uygundur. Birinci basamak uygulamadan yarar göremeyen hastalara uygulanabilir. Hastanın belli başlı güçlükleri öğrenilir. Hastanın değerlendirilmesi sonucunda, o hastanın tedavi hedefleri ve beklentileriyle uyumlu tıbbi tedavisine ek kısa süreli bireysel veya grup terapisi, ilaç tedavisi veya daha kapsamlı bir tedavi önerisinde bulunulur. ${ }^{[6]}$

\section{Üçüncü basamak}

Ağrı tedavisinde uygulanan birinci basamak medikal tedaviler ve psikososyal uygulamalara rağmen halen ağrı yakınması olan ve buna bağlı yeti-yitimi yaşayan hastalara uygulanır. Bu gruptaki hastaların karmaşık tıbbi ve sosyal öyküleri olabilir. Bu hastaların yönetiminde, multidisipliner yaklaşımla ağrı tedavisi uygulanmalıdır. ${ }^{[6]}$

\section{Kronik Ağrıda Kanıta Dayalı Psikiyatrik Tedaviler}

\section{ilaç-dışı tedaviler}

Ayaktan hasta birimlerine en sık somatik başvuru nedeni ağrı iken, en sık ruhsal başvuru nedeni depresyondur. Kroenke ve arkadaşları "Affektif bozukluklar ve kas-iskelet ağrısında basamaklı bakım” başlıklı randomize kontrollü çalışmalarında, kronik ağrı ve komorbid depresyonu olan hastalarda farmakolojik tedaviler ile öz-yönetim müdahalelerini birleştirerek ağrı ve depresyon üzerine etkisini araştırmışlardır. Olağan bakımla karşılaştırıldığında; ilaç ve öz-yönetim müdahaleleri birlikte uygulandıklarında depresyonda belirgin bir düzelme sağlamış; ağrı şiddeti ve yeti-yitiminde ise orta düzeyde bir gerileme sağlamıştır. ${ }^{[10]}$
Multidisipliner biyo-psikososyal rehabilitasyon programları, fiziksel, psikolojik, eğitim ve işle ilgili birleşenlerin birleşmesinden oluşur ve farklı tıp dallarında bu alanlarda uzmanlaşmış kişilerce yapılır. Kronik bel ağrısında multidisipliner rehabilitasyonun, ağrı, yeti-yitimi ve çalışma durumu üzerine etkilerinin araştırıldığı bir sistematik derleme ve meta-analizde, bu konu ayrıntılı ve titiz bir şekilde ele alınmıştır. ${ }^{[4]}$ Yazarlar, sadece randomize kontrollü çalışmalardan, hakemli dergilerde yayımlanan araştırmaları gözden geçirmişlerdir. Kronik bel ağrısı üç aydan daha uzun süren ağrı olarak tanımlanırken, enfeksiyon veya tümör gibi nedeni belli kronik bel ağrıları ile ilgili çalışmalar dışlanmış, sadece disk dejenerasyonu, disk herniyasyonu, faset eklem disfonksiyonu ya da sakroiliak eklem ağrısı olan hastalar ele alınmıştır. Çalışmada, birincil sonlanım kriterleri ağrı, yeti-yitimi ve çalışma durumu; ikincil sonlanım kriterleri psikolojik işlevsellik, yaşam kalitesi, yan etkiler ve sağlık sistemlerinin kullanımı olarak belirlenmiştir. Sonuçlar; kısa (0-3 ay), orta (3-12 ay) ve uzun (12 ay ve daha uzun) vadeli olarak sunulmuştur. Multidispliner rehabilitasyon, fiziksel tedaviler (sıcak ve elektroterapötik modaliteler, aerobik germe ve güçlendirme egzersizleri, eğitim bel okulu gibi, manuel terapiler), olağan ba$\mathrm{kım}$, bekleme listesi ve cerrahi grup ile karşılaştırılmıştır. Multidispliner rehabilitasyon, olağan bakım ile karşılaştırıldığında, ağrı ve yeti-yitimini azaltmada olağan bakıma göre daha etkili (orta düzeyde etki) bulunmuştur. Çalışma durumu açısından aralarında bir fark bulunmamıştır. Fiziksel tedaviler ile karşılaştırıldığında; uzun vadede ağrı açısından fark yok iken, yeti-yitimi ve çalışma durumu açısından multidispliner rehabilitasyon daha etkili bulunmuştur. Yan etki açısından aralarında fark bulunmamıştır. Multidisipliner rehabilitasyon cerrahi ile karşılaştıııldığında; iki çalışmanın (biri iş durumuyla ilgili sonuç bildirmemiş) sonuçları değerlendirilmiş; uzun vadede ağrı, yeti-yitimi, çalışma durumu açısından fark bulunmamıştır. Bekleme listesi ile karşılaştırıldığında, uzun vadeye ilişkin veri olmaması nedeniyle sonuçlar bildirilmemiştir. Üç çalışmaya dayanan kısa vade sonuçlarına göre, multidisipliner rehabilitasyonun ağrı ve yeti-yitimini azalttığı bulunmuştur. Yazarlar, bu derleme ve meta-analiz sonuçlarıla ilgili multidisipliner rehabilitasyon uygulamalarının, uzun vadede ağrı ve yeti-yitimi açısından, olağan bakıma (orta düzey kanıt) ve fiziksel tedavilere (düşük düzey kanıt) göre daha etkili olduğu ve işe dönme açısından uzun vadede multidisipliner rehabilitasyon uygulamalarının fiziksel tedavilere göre etkili olduğu sonucuna varmışlardır. ${ }^{[4]}$

Literatür bilgisi, günümüzde kanıta dayalı tedaviler içerisinde, ağrı hastalarında en etkili terapi yönteminin Bilişsel Davranışçı Terapi (BDT) olduğunu söyler. ${ }^{[6]}$ BDT'de, işe yaramayan biliş̧ler ve davranışların (ağrının 
devam etmesi, alevlenmesine katkıda bulunan bilişler ve davranışlar), daha adaptif ve gerçekçi düşüncelerle ve davranışlarla yer değiştirmesi hedeflenir. BDT'nin anahtar bileşenleri şunlardır:

a) Bilişsel yeniden yapılandırma: Hastaya işe yaramayan düşüncelerini nasıl değiştireceği öğretilir.

b) Relaksasyon eğitimi: Hastaya diyafragmatik nefes alma, yönlendirilmiş imgelem gibi tekniklerle gevşeme ve rahatlama sağlayacağı teknikler öğretilir.

c) Zaman odaklı aktivitelerin hızını ayarlamak: Hastaya bir şeyi gereğinden fazla yapmayarak nasıl daha aktif olunabileceği öğretilir.

d) Ev ödevleri: Bu ödevler basitten zora doğru derecelendirilir. Başlangıçta hastaya, ağrı nedeniyle oluşan kısıtlanmalarına yönelik, daha az zorlanacağı aktivite ödevleri verilir. Bu ödevlerde amaç, hastayı daha aktif bir yaşama adapte etmek veya daha aktif olacağı yaşam tarzı değişikliklerini ona sunmaktır. ${ }^{[6,11]}$ Hastaya günlük aktivitesini arttırmaya yönelik egzersiz içeren ev ödevleri de verilebilir; günlük aktivite çizelgesi yapması istenir.

Kronik ağrılı durumlarda BDT'nin, hastanın felaketleştirici düşüncelerini azaltarak ve hastanın öz-etkinliğini arttırarak, kronik ağrıyla ilişkili problemlerin düzelmesinde yarar sağladığına inanılır. Farkındalık temelli stres azaltma terapisinde ise, kronik ağrılı hastanın mevcut durumuyla ilgili farkındalığını ve ağrı kabulünü arttırarak yarar sağlandığı kabul edilir. Kronik bel ağrısı olan hastalarda BDT ve farkındalık temelli stres azaltma terapisinin olağan bakımla randomize edildiği bir yıllık izlem çalışmasının sonuçlarına göre; bir yıl sonunda, her iki terapinin de olağan bakıma kıyasla felaketleştirmeyi azalttı̆̆ı, her iki terapi yönteminin kabullenme ve farkındalık yaratma açısından farksız ve olağan bakımdan daha üstün oldukları bulunmuştur. ${ }^{[12]}$

Sistematik araştırmalar üzerinde yapılan gözden geçirme yazıları, psikolojik müdahalelerin, kronik kasiskelet ağrısı, özellikle sırt ağrısı tedavisinde etkili olduğunu doğrulamaktadır. ${ }^{[13]}$

\section{ilaç tedavileri}

Psikiyatrik hastalıklarda ağı, çok sık karşımıza çıkan bir belirtidir. Depresyon ve ağrının üst üste binmesi \%30-60 gibi bir sıklıkta karşımıza çıkar. Depresyonun ortaya çıkması ve sürmesinde, ağrı güçlü bir öngörü faktörüdür. Aynı zamanda depresyon da ağrı için güçlü bir öngörü faktörüdür. Bunlardan birinin tek başına olmasına kıyasla depresyon ve ağrının birlikte görülmesi, daha fazla yeti-yitimine işaret eder. ${ }^{[14]}$ Dünya Sağlık Örgütü tarafından organize edilen ve 17 ülkenin dahil olduğu bir çalışmada, ağrısı olan yetişkinlerde ağrı; depresyon ve anksiyete bozuklukları ile ilişkili bulunurken, alkol kullanım bozuklukları ile ilişkili bulunmamıştır. ${ }^{[15]}$

Kroenke ve arkadaşları, kas-iskelet sistemi ağrıları, nöropatik ağrı, kronik bel ağrısı ve osteoartrite bağlı ağrı durumlarında uygulanan farmakolojik tedavilerle ilgili yapılan sistematik derlemeleri yorumlayarak ve sentezini yaparak yazdıkları, "Kronik ağrıda ilaç tedavileri" başlıklı çalışmalarında; kronik ağrıda antidepresanların kullanımlarına ilişkin önemli bilgiler sunmuşlardır. ${ }^{[14]}$

Antidepresanların analjezik etkileri altında yatan mekanizmalar içerisinde, N-metil-D aspartat (NMDA) ve adenozin reseptörlerini, sodyum kanallarını, serotonin, noradrenalin ve opioid sistemlerini etkilemesi yer alır. Ayrıca antidepresanların, duygudurum üzerine olan etkilerinden bağımsız olarak, membran stabilizasyonu, peptid sinerjizmi, antihistaminik etkileri ile ilişkili analjezik etkileri de vardır. ${ }^{[1]}$

Meta-analizler, antidepresanların kanser dışı kronik ağrıda semptom azalmasında orta düzeyde etki göstererek plaseboya üstün olduğunu bulmuştur. Antidepresanların daha çok, nöropatik ağrı, fibromiyalji, bel ağrısı ve baş ağrısında etkili oldukları gösterilmiştir. Özellikle nöropatik ağrıda kullanımları ve etkinliklerine ilişkin güçlü kanıtlar olduğu belirtilmektedir. ${ }^{[2]}$

Antidepresanlar içerisinde, trisiklik antidepresanlar (TSA) kronik ağrıda en uzun zamandır kullanılan ilaçlardır. Özellikle amitriptilin, desipramin ve nortiriptilin, en çok çalışılmış ve etkili olduğu gösterilmiş antidepresanlardır. ${ }^{[16]}$ Tipik olarak, TSA dozu ağrı tedavisinde depresyon tedavisinde kullanılan dozlara göre daha düşük dozlarda kullanılır. Genellikle uygulamalar 25-100 mg/gün ile sınırlıdır. Bazı hastalarda ilaç dozunu arttırmak yarar sağlayabilir. TSA'ların avantajlı yanları; ucuz olmaları ve uzun zamandır pratik uygulamada yer almalarıdır. Dezavantajları ise yan etkileridir. En sık gözlenen yan etkileri içerisinde, hipertansiyon, ortostatik hipotansiyon, taşikardi, aritmiler ve özellikle yaşlı hastalarda düşmelerdir. Yüksek dozlarda toksik ve ölümcül olduklarını da unutmamak gerekir.

Doksan altı randomize kontrollü çalışmanın incelendiği bir meta-analizde, 55 TSA çalışmasının \%76'sında TSA'ların ağrı açısından yarar sağladıkları belirtilirken, 17 serotonin gerialım inhibitörleri (SGAi) çalışmasının \%47'sinde olumlu sonuçlar elde edildiği ifade edilmiştir. ${ }^{[17]}$ İki antidepresanı kafa 
kafaya karşılaştıran çok az çalışma bulunmaktadır. Meta-regresyon yöntemiyle indirekt olarak antidepresanlar karşılaştırıldığında, antidepresan tipleri arasında fark bulunmazken, bivariate çetele işlemi ile karşılaştırıldıklarında, TSA'ların SGAílere daha üstün bulunduğu belirtilmiştir. Yazarlar, indirekt karşılaştırmaların, iki antidepresanın aynı çalışmada karşılaştırılmasına göre güvenilirliğinin daha düşük olduğunu belirtmektedirler. ${ }^{[18]}$ Başka bir derlemede, kronik ağrıda SGAi'lerin pek etkin olmadığı kanaatine varılmıştır. ${ }^{[19]}$ Genel olarak, SGAi'lerin analjezik etkilerinin TSA'lara göre nispeten daha az olduğunu söyleyebiliriz.

Serotonin noradrenalin gerialım inhibitörleri (SNGAi), kronik ağrıda kullanılan diğer bir antidepresan grubudur. Bu grupta, duloksetin, venlafaksin ve milnacipran yer almaktadır. Bu ilaçlar, TSA'lardan farklı olarak; sodyum kanallarını, kolinerjik ve adrenerjik reseptörleri etkilemez, dolayısıyla TSA'lara göre yan etkileri daha azdır ve daha iyi tolere edilir. Duloksetin ile yapılan 12 haftalık randomize plasebo kontrollü üç çalışmada, duloksetin diyabetik periferik nöropati tanılı hastalarda plaseboya üstün bulunmuştur. Bu çalışmalarda, duloksetinin ağrı giderici etkisinin, ilacın antidepresan etkisinden çok analjezik etkilerine bağlı oluştuğu belirtilmiştir. ${ }^{[18,20,21]}$ Duloksetin ayrıca, fibromiyaljide FDA onayı almıştır.

Genel olarak, SNGAi trisiklik antidepresanlara göre daha iyi tolere edilir, nöropatik ağrıda etkili olabileceği yönünde bilgiler mevcuttur. ${ }^{[16,22,23]}$

Venlafaksinin uzun salınımlı formuyla yapılan bir çalışmada, venlafaksin diyabetik nöropatide plaseboya üstün bulunmuştur. ${ }^{[24]}$ Venlafaksinin diğer ağrılı durumlarda da yararlı olabileceğine ilişkin bilgiler mevcuttur. ${ }^{[25]}$ Fakat ağrı tedavisinde henüz FDA onayı yoktur.

Depresyon tanılı hastalarla yapılan beş çalışmanın meta-analizinden elde edilen sonuçlara göre; duloksetinin istatistiksel anlamlı düzeyde analjezik etkisinin olmadığı bulunmuştur. ${ }^{[26]}$ Sekiz çalışmanın dahil edildiği bir meta-analizde, duloksetin plasebo veya paroksetin ile karşılaştırılmış, depresyonun ağrılı fiziksel semptomları üzerine etkisi araştırılmış ve duloksetinin analjezik etkisine dair yeterli kanıt olmadığı bildirilmiştir. ${ }^{[27]}$

Tüm bu depresyon çalışmalarında, ağrı ikincil sonlanım kriteri olarak belirlenmiştir; fakat, iki çalışma dışında kalan diğer çalışmalara alınan hastaların büyük bir kısmının ağrısı bulunmamaktadır. ${ }^{[14]}$ Başka bir çaIş̧mada, depresyonu ve orta düzeyde ağrısı olan hastalarda duloksetin plaseboya göre, hem depresyon hem de ağrı belirtilerinde yararı bulunmuştur. ${ }^{[28]}$
Sonuç olarak, kronik ağrılı durumlarda antidepresanlar içerisinden TSA'ların, antidepresan etkilerinden bağımsız analjezik etkilerinin olduğu ve özellikle nöropatik ağrıda etkili olabilecekleri söylenebilir. SNGAi'nin analjezik etkileriyle ilgili henüz TSA'lar kadar güçlü kanıtlar bulunmamaktadır.

Psikososyal müdahaleler medikal tedavilerle beraber uygulandıklarında, kronik ağrıda tedavi başarısının artacağı söylenebilir.

Tamamen psikiyatrik bir hastalığın belirtisi olarak karşımıza çıkan ağıılı durumların tedavisinde, psikiyatrik tedaviler (antidepresanlar, antipsikotikler, duygudurum dengeleyicileri ve psikoterapiler) esastır. Bu yazıda, psikiyatrik hastalıklara bağıı oluşan ağrılı durumların tedavisine değinilmemiştir.

\section{KAYNAKLAR}

1. Kutsal YG, Varlı K, Çeliker R, Özer S, Orer H, Aypar Ü, Şahin A, Oruçkaptan H. Ağrıya multidisipliner yaklaşım. Hacettepe Tıp Dergisi 2005;36:111-28.

2. Turk DC, Wilson HD, Cahana A. Treatment of chronic noncancer pain. Lancet 2011;377(9784):2226-35. Crossref

3. Eapen M, Eugene K, ZempskyW. PharmacologicalTreatment of Pain. Semin Pediatr Neurol 2016;23(3):209-19. Crossref

4. Kamper SJ, Apeldoorn AT, Chiarotto A, Smeets RJ, Ostelo RW, Guzman J, van Tulder MW. Multidisciplinary biopsychosocial rehabilitation for chronic low backpain: Cochrane systematic review and meta-analysis. BMJ 2015;350:h444. Crossref

5. Strauss A. The psychiatric model of treating chronic pain. PPM 2006;6(2). Available at: https://www.practicalpainmanagement.com/ treatments/psychological/psychiatric-model-treating-chronic-pain

6. Otis JD, Hughes DH. Psychiatry and Chronic Pain. Published on Psychiatric Times, December 15, 2010. Available at: http://mww. psychiatrictimes.com/special-reports/psychiatry-and-chronic-pain

7. Hughes D, Kleespies P. Suicide in the medically ill. Suicide Life Threat Behav 2001;31 Suppl:48-59.

8. Von Korff M. Pain management in primary care: an individualized stepped-care approach. In: Gatchel RJ, Turk DC, editors. Psychosocial factors in pain : Critical perspectives. New York (NY): Guilford Press; 1999. p.360-73.

9. Sobell MB, Sobell LC. Stepped care as a heuristic approach to the treatment of alcohol problems. J Consult Clin Psychol 2000;68(4):573-9.

10. Kroenke K, Bair MJ, Damush TM, Wu J, Hoke S, Sutherland J, Tu W. Optimized antidepressant therapy and pain selfmanagement in primary care patients with depression and musculoskeletal pain: a randomized controlled trial. JAMA 2009;301(20):2099-110. Crossref

11. Hoffman BM, Papas RK, Chatkoff DK, Kerns RD. Metaanalysis of psychological interventions for chronic low back pain. Health Psychol 2007;26(1):1-9.

12. Turner JA, Anderson ML, Balderson BH, Cook AS, Sherman $\mathrm{KJ}$, Cherkin DC. Mindfulness-based stress reduction and cognitive behavioral therapy for chronic low back pain: similar effects on mindfulness catastrophizing, self-efficacy and acceptance in a randomized controlled trial. Pain 2016;157(11):2434-44. 
13. Kröner-Herwig B. Chronic Pain Syndromes and their treatment by psychological interventions. Curr Opin Psychiatry 2009;22(2):200-4. Crossref

14. Kroenke K, Krebs EE, Bair MJ. Pharmacotherapy of chronic pain: a synthesis of recommendations from systematic reviews. Gen Hosp Psychiatry 2009;31(3):206-19. Crossref

15. Gureje O, Von Korff M, Kola L, Demyttenaere K, He Y, Posada-Villa J, Lepine JP, Angermeyer MC, Levinson D, de Girolamo G, Iwata N, Karam A, Guimaraes Borges GL, de Graaf R, Browne MO, Stein DJ, Haro JM, Bromet EJ, Kessler RC, Alonso J. Pain. The relation between multiple pains and mental disorders: results from the World Mental Health Surveys. Pain 2008;135(1-2):82-91.

16. Stayner RS, Ramezani A, Prased R, Mahajan G. Chronic pain and psychiatric illness managing comorbid conditions. Curr Psychiatry 2016;15(2):26-33.

17. O'Malley PG, Jackson JL, Santoro J, Tomkins G, Balden E, Kroenke K. Antidepressant therapy for unexplained symptoms and symptom syndromes. J Fam Pract 1999;48(12):980-90.

18. Perahia DG, Pritchett YL, Desaiah D, Raskin J. Efficacy of duloxetine in painful symptoms: an analgesic or antidepressant effect? Int Clin Psychopharmacol 2006;21(6):311-7.

19. Jung AC, Staiger T, Sullivan M. The efficacy of selective serotonin reuptake inhibitors for the management of chronic pain. J Gen Intern Med 1997;12(6):384-9.

20. Goldstein DJ, Lu Y, Detke MJ, Lee TC, lyengar S. Duloxetine vs. placebo in patients with painful diabetic neuropathy. Pain 2005;116(1-2):109-18.

21. Wernicke JF, Pritchett $Y L$, D'Souza DN, Waninger A, Tran $P$, lyengar S, Raskin J. A randomized controlled trial of duloxetine in diabetic peripheral neuropathic pain. Neurology 2006;67(8):1411-20.
22. Arnold LM, Lu Y, Crofford LJ, Wohlreich M, Detke MJ, lyengar $\mathrm{S}$, Goldstein DJ. A double-blind, multicenter trial comparing duloxetine with placebo in the treatment of fibromyalgia patients with or without major depressive disorder. Arthritis Rheum 2004;50(9):2974-84.

23. Arnold LM, Pritchett YL, D'Souza DN, Kajdasz DK, lyengar $\mathrm{S}$, Wernicke JF. Duloxetine for the treatment of fibromyalgia in women: pooled results from two randomized, placebocontrolled clinical trials. J Womens Health (Larchmt) 2007;16(8):1145-56.

24. Rowbotham M, Goli V, Kunz N, Lei D. Venlafaxine extended release in the treatment of painful diabetic neuropathy: a double-blind, placebo-controlled study. Pain 2004;110(3):697-706.

25. Grothe DR, Scheckner B, Albano D. Treatment of pain syndromes with venlafaxine. Pharmacotherapy 2004;24(5):621-9.

26. Spielmans GI. Duloxetine does not relieve painful physical symptoms in depression: a meta-analysis. Psychother Psychosom 2008;77(1):12-6.

27. Krebs EE, Gaynes BN, Gartlehner G, Hansen RA, Thieda P, Morgan LC, DeVeaugh-Geiss A, Lohr KN. Treating the physical symptoms of depression with second-generation antidepressants: a systematic review and meta-analysis. Psychosomatics 2008;49(3):191-8. Crossref

28. Brecht S, Courtecuisse C, Debieuvre C, Croenlein J, Desaiah D, Raskin J, Petit C, Demyttenaere K. Efficacy and safety of duloxetine $60 \mathrm{mg}$ once daily in the treatment of pain in patients with major depressive disorder and at least moderate pain of unknown etiology: a randomized controlled trial. J Clin Psychiatry 2007;68(11):1707-16. 